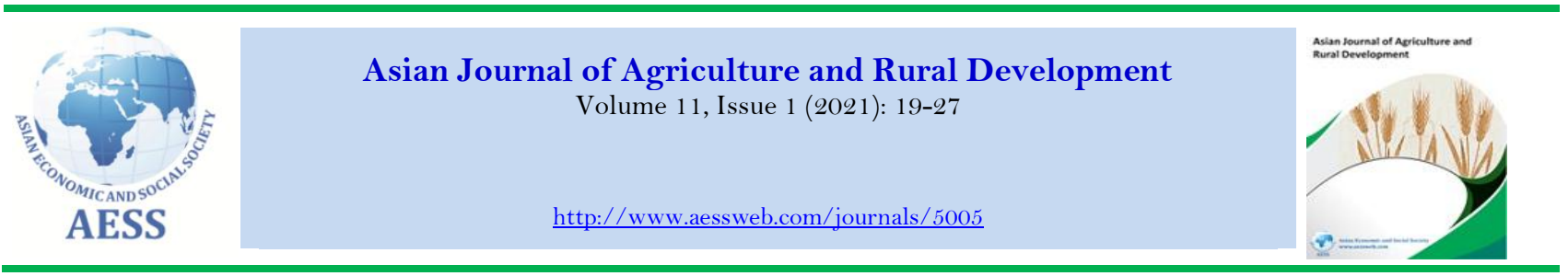

\title{
ANALYSIS OF SOIL TEXTURE, FURROW GEOMETRYAND INFILTRATION RATE FOR IMPROVING WATER APPLICATION EFFICIENCY
}

\author{
Duba Chena Dero ${ }^{a}$ \\ Kishor Purushottam \\ Kolhe $^{\text {b }}$
}

\author{
${ }^{a}$ Lecturer Department of Soil and Water Resources Engineering, College of Engineering \\ and Technology, Bule Hora University, Ethiopia. \\ ${ }^{b}$ Professor College of Engineering and Technology, Bule Hora University, Ethiopia.
}

ه skishor75@gmail.com (Corresponding author)

\begin{tabular}{l} 
Article History \\
\hline Received: 28 October 2020 \\
Revised: 2 December 2020 \\
Accepted: 30 December 2020 \\
Published: 18 January 2021
\end{tabular}

\section{Keywords}

Soil texture

Furrow geometry

Furrow parameters

Infiltration rate

Irrigation water

Irrigation efficiency

Soil moisture monitoring

Field capicity.

\begin{abstract}
Soil texture, furrow geometry, and infiltration rate are the main characteristics for improving water application efficiency. Substantial amounts of diverted irrigation water are often lost because of poor water control, inefficient irrigation conveyance systems, poor on-farm water management, or poor application practices. Field experiments were conducted on three farm plots within the command area for water availability and accessibility under the Melka Hida small-scale irrigation scheme in the West Guji Zone of Oromia Region, Ethiopia. The physical characteristics of soil, including depth, particle distribution, textural classification, bulk density, field capacity, and permanent wilting point, were studied and the results are presented. Furrow parameters including slope, width, length, and shape geometry were measured. The cumulative infiltration and infiltration rates were also recorded. The results show that irrigation application efficiency ranged from 57 to $64 \%$ with an average of $61 \%$, indicating that about $40 \%$ of the applied water was not used by crops. The storage efficiency ranged from 79.6 to $81.6 \%$ with an average of $80 \%$. Soil moisture measurements showed that crops were water stressed during the experimental period. Application efficiency decreased with increasingly steep slopes and cutoff times, greater applied depth, and high inflow rate in the study area. Unavailability of irrigation water control structure, weakness of water users' associations, and maintenance of furrows and steep slopes were observed as the major causes of inefficient water management in the Melka Hida irrigation scheme.
\end{abstract}

Contribution/Originality: This study contributes original research work carried out to solve the real problems of marginal farmers in the West Guji Zone of Oromia, Ethiopia. This study uses new estimation methodology for improvement of field irrigation effeiciency in the Melka Hida small-scale irrigation scheme, through soil moisture monitoring and water mangement.

DOI: 10.18488/journal.ajard.2021.111.19.27

ISSN(P): 2304-1455/ ISSN(E): 2224-4433

How to cite: Duba Chena Dero --- Kishor Purushottam Kolhe (2021). Analysis of Soil Texture, Furrow Geometry, and Infiltration Rate for Improving Water Application Efficiency. Asian Journal of Agriculture and Rural Development, 11(1), 19-27. 10.18488/journal.ajard.2021.111.19.27

(C) 2021 Asian Economic and Social Society. All rights reserved. 


\section{INTRODUCTION}

Water is the most important resource for life, since it is a basic need. With increased population growth and the erratic nature of rainfall, competition for water resources has increased. Due to water scarcity and drought, efficient application of irrigation water is expected in the context of increasing competition for water resources. Reliable and suitable use of irrigation water with appropriate system management can result in improvements in irrigation performance and ensure economic development (Mancosu, Snyder, Kyriakakis, \& Spano, 2015). The main purpose of irrigation is to restore water to the plant root zone, making it available to the crop as a whole. This may be accomplished by means of several procedures that can be grouped thus: overhead, surface, and subsurface.

Ethiopia has an irrigation potential of 5.3 million ha, of which 3.7 million ha can be developed using surface water sources and 1.6 million ha using groundwater and rainwater. Currently a number of irrigation projects are being implemented with huge resources to help overcome human struggle and the hardship of poverty. Despite their promise as engines of agricultural growth, the efficiency of irrigation schemes in this country has not reached full potential (Awulachew \& Ayana, 2011). According to the Food and Agriculture Organization (2011), 60\% of the fresh water diverted for agriculture globally does not contribute directly to food production. This amount of water is lost because of poor water control, inefficient irrigation systems with leaking conveyance and distribution, and poor onfarm water management and application practices. The FAO maintains that only about $40 \%$ of fresh water abstracted globally for irrigation is being used effectively for consumption in agriculture. Part of the water discharged in these systems is lost to saline groundwater. According to Beshir and Bekele (2006), Ethiopia's irrigation efficiency is generally low - around 25-50\% - and problems with rising water tables and soil salinization are now emerging. It is crucially important to measure application efficiency as a performance parameter in the use of irrigation water, to minimize wastage. Pearse (1973) suggested that improvement in surface irrigation efficiency is limited to the understanding of key factors such as soil type, topography, furrow shape, flow rate, and crop age that affect the performance of such systems. In the case of furrow irrigation, Holzapfel, Pannunzio, Lorite, Silva, and Farkas (2010) suggested that the correct selection of furrow irrigation variables - length, time of cutoff and discharges - improves irrigation scheduling and field water management. This may potentially reduce over-irrigation and deep percolation of applied irrigation water. Furrow length, width, shape, spacing, topography, and flow rate are among the parameters that were considered for evaluation of performance measures in the Melka Hida irrigation scheme. The efficient use of irrigation water is highly important due to the rapid increase in the world's population, particularly in developing countries where great potential for increasing food production and rural incomes is often found in areas under irrigation. This has become a very serious challenge in recent years and, despite the very high costs involved; the performance of many irrigation schemes has fallen far short of expectations (Food and Agriculture Organization, 1989).

To fill this knowledge gap, the present study was carried out on the Melka Hida surface irrigation scheme, constructed in 1999 by the government. It has an irrigation potential of 80 ha, and around 200 households are currently benefiting from it. Despite deterioration in its biophysical appearance, no evaluation of water application efficiency has been carried out to identify constraints and improve efficiency. Hence, it was deemed necessary to evaluate water application efficiency and devise the required improvements. The Melka Hida small-scale irrigation system is located in the Oromia Regional State of Ethiopia, West Guji Administrative Zone.

Irrigation development constitutes a major requirement and benefit for agricultural development and food security strategies. On the down side, irrigation schemes have the potential to degrade soil and waste valuable water resources if they are mismanaged. In recognition of both the benefits and disadvantages, assessment and evaluation of irrigation scheme efficiency has now become of paramount importance, not only to determine where the problems lie, but also to identify alternatives that may be both effective and feasible in improving efficiency (Abebe, 2015). This paper reports the results of recent research on soil physical properties, furrow geometry, and infiltration rate with the aim of improving water application efficiency.

\section{MATERIALS AND METHODS}

The field experiments were conducted on three farm plots within the command area, with water availability and accessibility being key for selection of plots. These plots were selected through communication and discussion with irrigation users, with input from kebele administrations and Gelana district irrigation office experts. The three selected plots are situated at the head (Feleke farm, H1), middle (Geremew farm, M1), and tail (Wako farm, T1) of the irrigation scheme. A detailed description of the experimental plots and crops grown in the study area is shown in Table 1.

Table 1. Description of the experimental plots and crops grown.

\begin{tabular}{c|c|c|c|c|c}
\hline Field ID & Area $\left(\mathbf{m}^{2}\right)$ & Crop & $\begin{array}{c}\text { Growing stage at start } \\
\text { of experiment (days) }\end{array}$ & $\begin{array}{c}\text { Planting } \\
\text { date }\end{array}$ & $\begin{array}{c}\text { Harvesting } \\
\text { date }\end{array}$ \\
\hline Head $\left(\mathrm{H}_{1}\right)$ & 510 & Tomato & 45 & $4 / 1 / 2017$ & $5 / 5 / 2017$ \\
\hline Middle $\left(\mathrm{M}_{1}\right)$ & 672 & Tomato & 40 & $9 / 1 / 2017$ & $10 / 5 / 2017$ \\
\hline Tail $\left(\mathrm{T}_{1}\right)$ & 375 & Tomato & 48 & $1 / 1 / 2017$ & $2 / 5 / 2017$ \\
\hline Head $\left(\mathrm{H}_{1}\right)$ & 510 & Tomato & 45 & $4 / 1 / 2017$ & $5 / 5 / 2017$ \\
\hline Middle $\left(\mathrm{M}_{1}\right)$ & 672 & Tomato & 40 & $9 / 1 / 2017$ & $10 / 5 / 2017$ \\
\hline Tail (T $\left(\mathrm{T}_{1}\right)$ & 375 & Tomato & 48 & $1 / 1 / 2017$ & $2 / 5 / 2017$ \\
\hline Source: Field data, 2017. &
\end{tabular}


The experiments were conducted with three replications (furrows) in each of the experimental blocks; the selected replications in each plot were separated by a distance of 8-11 m. Immediately after selection of replications from each plot, wooden marker posts were installed to identify the selected replications from other furrows, as shown in Figure 1.

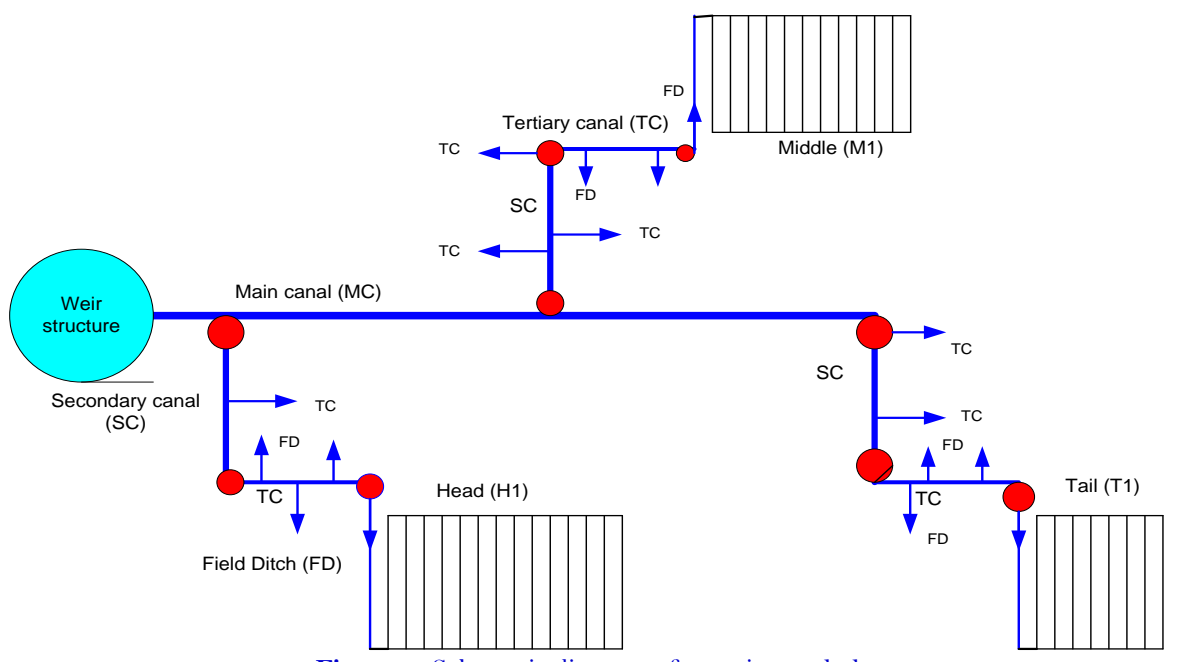

Figure 1. Schematic diagram of experimental plots.

\subsection{Fieldwork for Primary Data Collection}

Soil texture, field capacity (FC), permanent wilting point (PWP), and bulk density of the experimental fields were determined in the laboratory. Soil samples were collected from the three experimental plots at depths of $0-30$, 30-60, and 60-90 cm using a core sampler. Locations of soil sampling in the experimental plot are shown in Figure 2. Soil samples were collected using a diagonal technique and mixed thoroughly according to recommendations (Thakur, Baghel, Sharma, Sahu, \& Amule, 2012). In the process of sampling, the core sampler was inserted into the soil without disturbing the arrangement and structure of the soil using hammered metal. A sampling code was given to each soil sample based on pit, replication, and farm plots, to identify and analyze soil data without confusion.

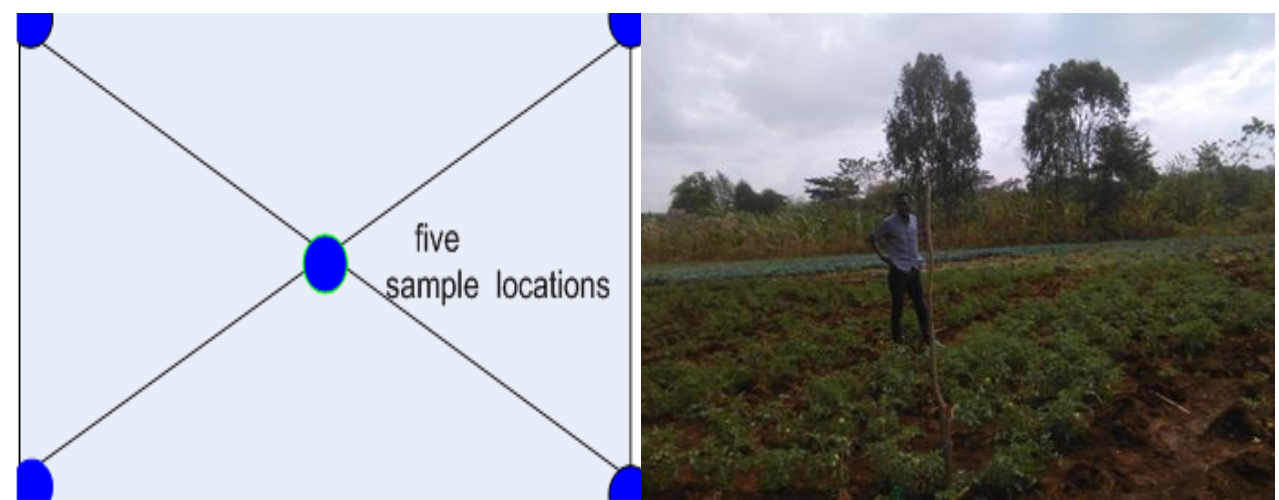

Figure 2. Location of sampling sites in the experimental plot.

In the laboratory, hydrometry was used to determine soil particle distribution while the USDA SCS soil textural triangle method was used to establish soil textural classification. The laboratory testing procedure on soil samples is presented in Figure 3. Bulk density of the soil was computed using Equation 1:

$$
\rho b=\frac{M_{s}}{V_{t}}
$$

where $\rho_{b}$ is the bulk density of soil $\left(\mathrm{cm}^{-3}\right), M_{s}$ is the weight of oven-dried soil $(\mathrm{g})$, and $V_{t}$ is the total volume of soil $\left(\mathrm{cm}^{3}\right)$.

Soil FC and PWP were determined using a pressure plate apparatus at 1/3 and 15 bar, respectively. Moisture content was computed gravimetrically, by applying Equation 2: 


$$
\theta_{m}=\frac{M_{w}}{M_{S}} \times 100
$$

where $\theta_{m}$ is soil moisture content expressed on a mass basis (\%), Mw is mass of water $(\mathrm{g})$, and $M s$ is mass of ovendried soil $(\mathrm{g})$. Volumetric water content was determined from the gravimetric content using Equation 3:

$$
\theta_{v}=\theta_{m} \frac{\left(\rho_{b}\right)}{\left(\rho_{w}\right)}
$$

where $\theta_{v}$ is volumetric water content $(\%)$ and $\rho_{w}$ is water density $\left(\mathrm{g} / \mathrm{cm}^{-3}\right)$.

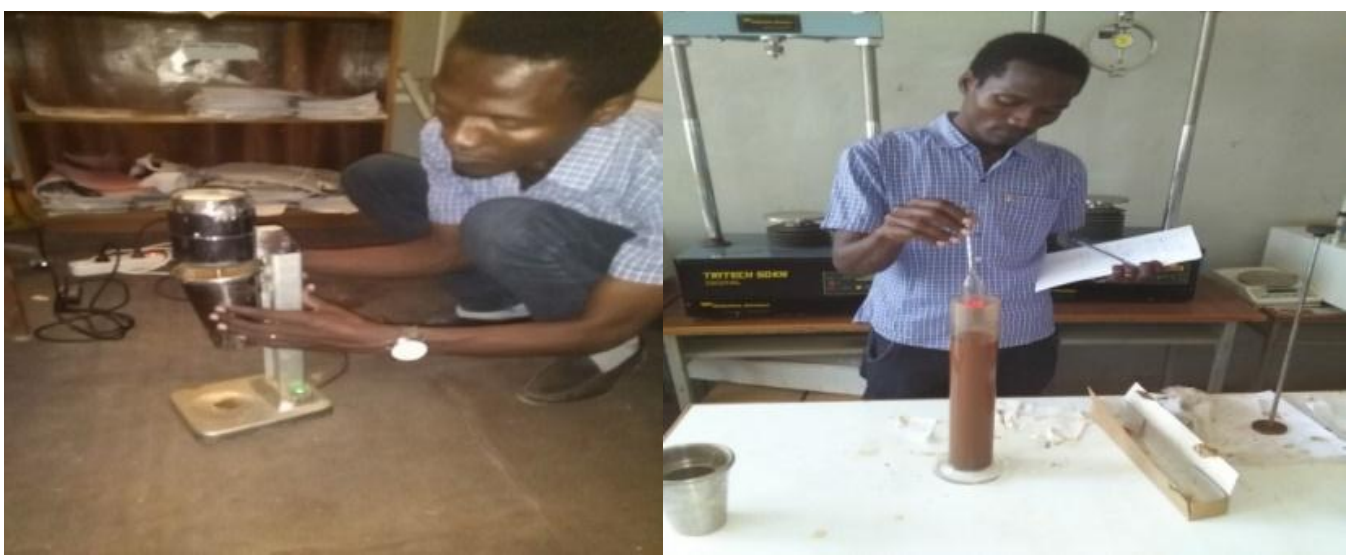

Figure 3. Laboratory test of soil samples.

Soil infiltration rate was determined in the field using a double-ring infiltrometer (Figure 4).

Total available soil water was computed using Equation 4:

$$
T A W=10\left(\theta_{f c}-\theta_{p w p}\right) \times Z_{r}
$$

where $T A W$ is total available water $(\mathrm{mm}), \theta_{f c}$ is moisture content at $\mathrm{FC} \mathrm{(vol} \mathrm{\% ),} \theta_{p \text { pup }}$ is moisture content at PWP (vol $\%)$, and $Z_{r}$ is rooting depth $(\mathrm{m})$.

In this study, furrow length, width, depth, and spacing were measured for each replicate at all three farm plots using measuring tape, spirit level, ropes, and stakes (Kulapongse, 1966).

Furrow slope was measured at two locations along each replicate using Equation 5:

$$
S=\frac{V}{H}
$$

where $S$ denotes furrow slope (-), $V$ is vertical distance $(\mathrm{m})$, and $H$ is horizontal distance $(\mathrm{m})$.

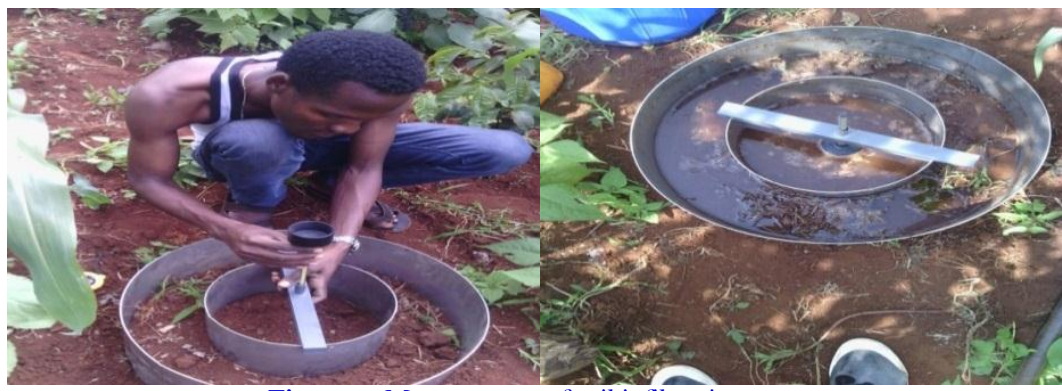

Figure 4. Measurement of soil infiltration rate.

\subsection{Field Application Efficiency}

As reported by the Food and Agriculture Organization (2002), furrow application efficiencies of 50-70\% are commonly reported, $85-90 \%$ are periodically reported from studies incorporating careful soil moisture monitoring, and performance may be acceptable if water application efficiency is $>70 \%$. Application efficiency is computed using Equation 6, and the depth of water stored in the root zone was calculated by Equation 7:

$$
E a=\frac{D_{s}}{D_{f}} \times 100
$$

where $E_{a}$ is application efficiency (\%), $D_{s}$ is the actual volume of irrigation water stored in the root zone (mm), and $D_{f}$ is water delivered to the field or farm $(\mathrm{mm})$. Ds was estimated thus:

$$
D_{s}=M_{c} \times A s g \times Z_{r}
$$

Where $D_{s}$ is the depth of water stored in the root zone (mm), M.c is the moisture content of soil (\%), Asg is the apparent specific gravity of soil, and $Z_{r}$ is the depth of the root zone $(\mathrm{m})$. 


\section{RESULTS AND DISCUSSION}

\subsection{Analysis of Physical Characteristics of Soil}

The soil texture in the experimental field is dominated by clay loam and loam, which is red in color. Soil particle distribution and textural classification of the topmost $90 \mathrm{~cm}$ are presented in Table 2. Percentage particle size distribution across the experimental plots showed no significant variation. The topmost $30 \mathrm{~cm}$ is dominated by clay loam in all experimental plots; the middle $30-60 \mathrm{~cm}$ is predominantly clay loam near $\mathrm{H} 1$ and $\mathrm{T} 1 \mathrm{but}$ is loam in M1. The topmost $90 \mathrm{~cm}$ of $\mathrm{T} 1$ is clay loam while the bottom $60-90 \mathrm{~cm}$ is loam; a higher percentage of sand is present in both $\mathrm{H} 1$ and M1. The average soil texture is dominated by clay loam and, in general, shows no significant variation across the experimental field.

Soil texture is one of the most basic soil characteristics influencing infiltration, moisture, and drainage. According to the Food and Agriculture Organization (1992), a clay loam soil with a depth of $90 \mathrm{~cm}$ is often chosen as optimal for crop production under average management. The proximity of our experimental plots to each other is one of the reasons for the uniformity of soil texture across the site. The soil texture in the study area is good in regard to water-storage capacity and crop production. For this soil type, good irrigation performance should be expected under effective irrigation system management.

Table 2. Results of soil particle distribution and textural classification.

\begin{tabular}{c|c|c|c|c|c|c}
\hline \multirow{2}{*}{ Experimental plot } & \multirow{2}{*}{ Soil depth $(\mathbf{c m})$} & \multicolumn{2}{|c|}{ Soil particle distribution $\mathbf{( \% )}$} & \multirow{2}{*}{ Textural classification } \\
\cline { 3 - 5 } & Sand & Silt & Clay & Clay loam \\
\hline Head $\left(\mathrm{H}_{1}\right)$ & $0-30$ & 37 & 24 & 39 & Clay loam \\
\hline & $30-60$ & 31 & 29 & 40 & Loam \\
\hline & $60-90$ & 40 & 35 & 25 & Clay loam \\
\hline Middle $\left(\mathrm{M}_{1}\right)$ & $0-30$ & 29 & 34 & 37 & Loam \\
\hline & $30-60$ & 34 & 41 & 25 & Loam \\
\hline Tail $\left(\mathrm{T}_{1}\right)$ & $60-90$ & 34 & 39 & 27 & Clay loam \\
\hline & $0-30$ & 26 & 38 & 36 & Clay loam loam \\
\hline & $30-60$ & 21 & 39.5 & 39 & Clay loam \\
\hline Average & $60-90$ & 27 & 33 & 40 & 37 & \\
\hline
\end{tabular}

\subsection{Bulk Density, FC, and PWP}

Bulk density, FC and PWP of the experimental plots were determined in the laboratory for the topmost $90 \mathrm{~cm}$ of soil, and are presented in Table 3. Bulk density is a key soil property because it is used to estimate water-holding capacity. The bulk density of soil in the study area was 1.25 and $1.36 \mathrm{~g} / \mathrm{cm}^{-3}$ for clay loam and loam, respectively. This is in agreement with results found in the literature, which describe a range of $1.2-1.5 \mathrm{~g} / \mathrm{cm}^{-3}$ for medium soil (Ministry of Agriculture, 2011). Bulk density increased with soil depth in our experimental plots except for M1, which was low at a depth of $60-90 \mathrm{~cm}$. This shows that soil compaction increases from top-down. This bulk density value demonstrates that both soil aeration and water-holding capacity are high across the plot. Therefore, under gentle slopes, soil erosion would not expected with such a level of bulk density.

Table 3. Results for bulk density, FC, and PWP

\begin{tabular}{|c|c|c|c|c|}
\hline Plot & \multicolumn{4}{|c|}{ Soil depth $(\mathrm{cm})$} \\
\hline $\operatorname{Head}\left(\mathrm{H}_{1}\right)$ & $0-30$ & $30-60$ & $60-90$ & Average \\
\hline$\rho_{b} \mathrm{~g} / \mathrm{cm}^{-3}$ & 1.25 & 1.31 & 1.36 & 1.3 \\
\hline $\mathrm{FC}$ (vol. \%) & 29.2 & 29.5 & 28.1 & 29 \\
\hline PWP (vol. \%) & 13.3 & 14.5 & 13 & 13.6 \\
\hline $\mathrm{TAW}(\mathrm{mm} / \mathrm{m})$ & 159 & 150 & 151 & 155 \\
\hline Middle $\left(\mathrm{M}_{1}\right)$ & $0-30$ & $30-60$ & $60-90$ & Average \\
\hline$\rho_{b} \mathrm{~g} / \mathrm{cm}^{-3}$ & 1.29 & 1.35 & 1.27 & 1.31 \\
\hline FC (vol. \%) & 30.5 & 29 & 29.2 & 29.6 \\
\hline PWP (vol. \%) & 13.6 & 13.2 & 11.4 & 12.7 \\
\hline $\mathrm{TAW}(\mathrm{mm} / \mathrm{m})$ & 169 & 158 & 178 & 169 \\
\hline Tail $\left(\mathrm{T}_{1}\right)$ & $\mathrm{O}-30$ & $30-60$ & $60-90$ & Average \\
\hline$\rho_{b} \mathrm{~g} / \mathrm{cm}^{-3}$ & 1.27 & 1.33 & 1.34 & 1.33 \\
\hline $\mathrm{FC}($ vol. \%) & 30.7 & 28.7 & 29.8 & 29.8 \\
\hline PWP (vol. \%) & 14.2 & 13.8 & 13.1 & 13.7 \\
\hline $\mathrm{TAW}(\mathrm{mm} / \mathrm{m})$ & 165 & 149 & 167 & 163 \\
\hline
\end{tabular}

Based on volumetric method, the average $\mathrm{FC}$ of the topmost $90 \mathrm{~cm}$ soil layer was 29, 29.6, and 29.8\% at $\mathrm{H} 1, \mathrm{M} 1$, and $\mathrm{T} 1$, respectively. This shows that the FC of the Melka Hida irrigation scheme is almost uniform across the area. 
The recommended values for soil $\mathrm{FC}$ range from $15-30 \%$ and $12-18 \%$ for clay loam and loam, respectively. The $\mathrm{FC}$ values of the study area are higher than those recommended in the literature for medium soil texture.

The average PWP of the topmost $90 \mathrm{~cm}$ soil layer was 13.6, 12.7, and 13.7\% at $\mathrm{H} 1, \mathrm{M} 1$, and T1, respectively. The recommended range for PWP is $7-16$ and $6-10 \%$ for clay loam and loam, respectively (Michael et al., 1972). As such, the PWP of the study area is marginally within the values recommended in the literature. The uniformity of FC and PWP across the experimental field is due to the uniformity of the soil texture in the study area. The available soil water of the topmost $90-\mathrm{cm}$ layer ranged between 155 and $169 \mathrm{~mm} / \mathrm{m}$; the water-holding capacity of medium soils is expected to be $100-180 \mathrm{~mm} / \mathrm{m}$ (Michael et al., 1972). The soil moisture available is also virtually uniform across the plots, i.e., the moisture-holding capacity of the Melka Hida irrigation scheme is within the range of values described in the literature. This implies that the field has high water-storage capacity that will be beneficial in yielding enhanced agricultural production.

\subsection{Furrow Slope and Dimensions}

Furrow slope was estimated for the experimental plots (Figure 6) using Equation 5; slope varied between 1 and $2 \%$ : the average at $\mathrm{H} 1, \mathrm{M} 1$, and $\mathrm{T} 1$ was $1.45,1.1$, and $1.7 \%$, respectively. In the experimental plots, average maximum $(1.7 \%)$ and minimum (1.1\%) slopes were at $\mathrm{T} 1$ and $\mathrm{M} 1$, respectively. Slope showed significant variation even between replicates in the same experimental plot. Maximum slope variation was $0.5 \%$, at T1,. These values are outside the limits recommended in the literature - 0.2-0.4\% for medium soil (Michael et al., 1972).

Our results show that the study area was dominated by a marginally suitable degree of slope in regard to surface irrigation, which has certain limitations. Slope is among the major topographic criteria regarding the suitability of surface irrigation as it is largely responsible for runoff and soil erosion, and the findings from our study area imply a potential erosion problem. It was observed that the challenge of soil erosion was of major consideration in the irrigation scheme. To deal with the soil erosion problem in yhe study area, permissive stream size should be applied (Figure 5). Farmers had constructed their furrows almost horizontally to reduce soil erosion and water wastage, especially at T1. Despite the best efforts of users, due to the gap in scientific knowledge, soil erosion and water losses remain of great concern in the irrigation scheme. Losses of this precious resource were due to the steep slopes, which were identified as the key factor affecting performance in the study area.

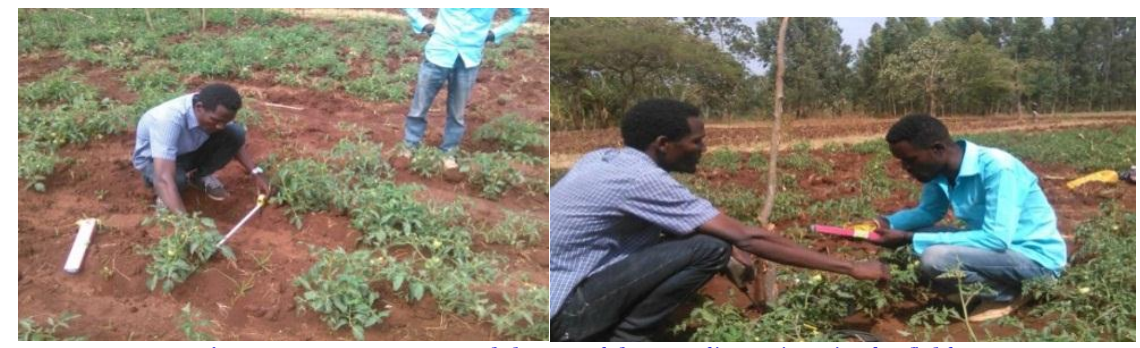

Figure 5. Measurement of slope and furrow dimensions in the field.

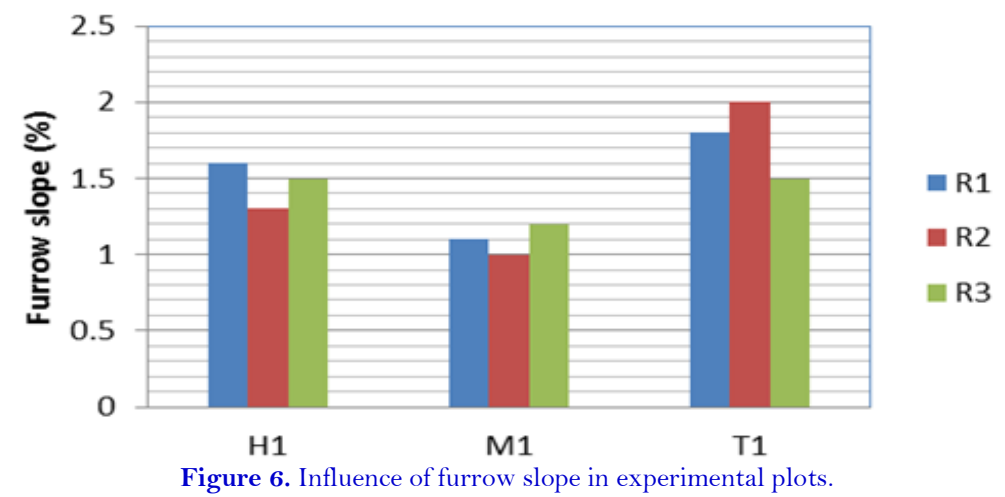

Note: R1,R2,R 3 :Replications of $\mathrm{H} 1, \mathrm{M} 1, \mathrm{~T} 1$ for irrigations events 1,2 and 3.

\subsection{Soil Infiltration Rate}

The infiltration rate of soil in the irrigation scheme was determined for the three experimental plots by field measurement (Figure 7). The initial infiltration rate rapidly decreased as the soil was wetted, and infiltration reached the basic rate almost after $3 \mathrm{~h}$. Basic infiltration rate determined for $\mathrm{H} 1$, M1, and T1 was 8.5, 9.0, and $11.25 \mathrm{~mm} / \mathrm{h}$, respectively. According to the Food and Agriculture Organization (2002), the recommended optimum infiltration rate for gravity irrigation is between 7 and $35 \mathrm{~mm} / \mathrm{h}$; for clay loam and loam this ranges between 5 and $10 \mathrm{~mm} / \mathrm{h}$, respectively. Hence, the basic infiltration rate for $\mathrm{H} 1$ and $\mathrm{M} 1$ was within the recommended range, while for $\mathrm{T} 1$ it was slightly higher. This may be due to land management conditions, because infiltration rate is markedly influenced by the condition of the soil surface. In regard to the ideal infiltration rate, the time for which irrigation water is applied must be properly managed to avoid deep percolation. At T1, due to furrow alignment, severe deep percolation was a problem that farmers did not take into account. The efficiency of irrigation application can be increased by using an 
appropriate inflow rate no greater than the soil infiltration rate. In general, the basic soil infiltration rate in the study area was within the optimum infiltration rate range for the gravity irrigation method (Tables 4-6).

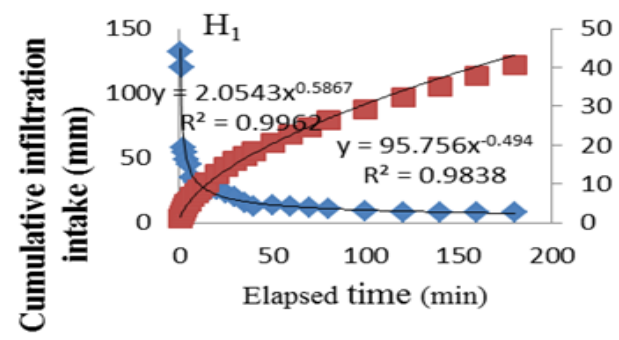

- Infiltration rate $(\mathrm{mm} / \mathrm{hr})$

cumulative infiltration $(\mathrm{mm})$

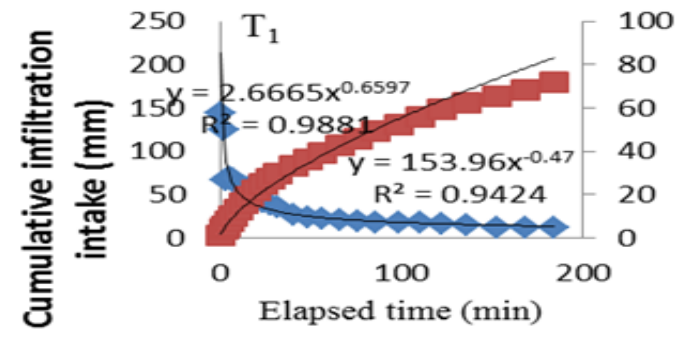

- Infiltration rate $(\mathrm{mm} / \mathrm{hr})$

cumulative infiltration $(\mathrm{mm})$

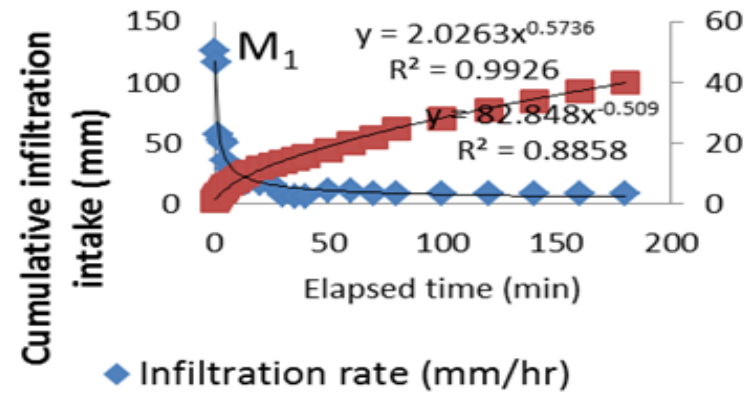

cumulative infiltration $(\mathrm{mm})$

Figure 7. Cumulative infiltration $(\mathrm{mm})$ and infiltration rate $(\mathrm{mm} / \mathrm{h})$ in the experimental plots.

Table 4. Infiltration rate and cumulative infiltration at $\mathrm{H} 1$.

\begin{tabular}{|c|c|c|c|c|c|c|}
\hline $\begin{array}{l}\text { Elapsed } \\
\text { time } \\
(\mathrm{min})\end{array}$ & $\begin{array}{c}\text { Time } \\
\text { interval } \\
\text { (min) }\end{array}$ & Time (h) & $\begin{array}{c}\text { Average } \\
\text { intake } \\
(\mathrm{mm})\end{array}$ & $\begin{array}{c}\text { Average } \\
\text { infiltration } \\
\text { rate } \\
(\mathrm{mm} / \mathrm{min})\end{array}$ & $\begin{array}{c}\text { Average } \\
\text { infiltration } \\
\text { rate }(\mathrm{mm} / \mathrm{h})\end{array}$ & $\begin{array}{c}\text { Average } \\
\text { cumulative } \\
\text { infiltration } \\
(\mathrm{mm})\end{array}$ \\
\hline $\mathrm{O}$ & $\mathrm{O}$ & $\mathrm{O}$ & $\mathrm{O}$ & $\mathrm{O}$ & & \\
\hline 0.5 & 0.5 & 0.00833333 & 1.1 & 2.2 & 132 & 1.1 \\
\hline 1 & 0.5 & 0.00833333 & 1 & 2 & 120 & 2.1 \\
\hline 2 & 1 & 0.01666666 & 0.97 & 0.97 & 58.2 & 3.07 \\
\hline 3 & 1 & 0.01666666 & 0.91 & 0.91 & 54.6 & 3.98 \\
\hline 4 & 1 & 0.01666666 & 0.81 & 0.81 & 48.6 & 4.79 \\
\hline 5 & 1 & 0.01666666 & 0.75 & 0.75 & 45 & 5.54 \\
\hline 7 & 2 & 0.03333333 & 1.15 & 0.575 & 34.5 & 6.69 \\
\hline 9 & 2 & 0.03333333 & 1.05 & 0.525 & 31.5 & 7.74 \\
\hline 11 & 2 & 0.03333333 & 0.96 & 0.48 & 28.8 & 8.7 \\
\hline 13 & 2 & 0.03333333 & 0.84 & 0.42 & 25.2 & 9.54 \\
\hline 15 & 2 & 0.03333333 & 0.75 & 0.375 & 22.5 & 10.29 \\
\hline 20 & 5 & 0.08333333 & 2.15 & 0.43 & 25.8 & 12.44 \\
\hline 25 & 5 & 0.08333333 & 1.9 & 0.38 & 22.8 & 14.34 \\
\hline 30 & 5 & 0.08333333 & 1.65 & 0.33 & 19.8 & 15.99 \\
\hline 35 & 5 & 0.08333333 & 1.3 & 0.26 & 15.6 & 17.29 \\
\hline 40 & 5 & 0.08333333 & 1.05 & 0.21 & 12.6 & 18.34 \\
\hline 50 & 10 & 0.16666666 & 2.32 & 0.232 & 13.92 & 20.66 \\
\hline 60 & 10 & O.16666666 & 2.1 & 0.21 & 12.6 & 22.76 \\
\hline 70 & 10 & 0.16666666 & 1.9 & 0.19 & 11.4 & 24.66 \\
\hline 80 & 10 & O.16666666 & 1.75 & 0.175 & 10.5 & 26.41 \\
\hline 100 & 20 & 0.33333333 & 2.96 & 0.148 & 8.88 & 29.37 \\
\hline 120 & 20 & 0.33333333 & 2.85 & 0.142 & 8.55 & 32.22 \\
\hline 140 & 20 & 0.33333333 & 2.85 & 0.142 & 8.55 & 35.07 \\
\hline 160 & 20 & 0.33333333 & 2.85 & 0.142 & 8.55 & 37.92 \\
\hline 180 & 20 & 0.33333333 & 2.85 & 0.142 & 8.55 & 40.77 \\
\hline
\end{tabular}


Table 5. Infiltration rate and cumulative infiltration at $\mathrm{M} 1$.

\begin{tabular}{|c|c|c|c|c|c|c|}
\hline $\begin{array}{c}\text { Elapsed } \\
\text { time } \\
(\mathrm{min}) \\
\end{array}$ & $\begin{array}{c}\text { Time } \\
\text { interval } \\
\text { (min) }\end{array}$ & Time (h) & $\begin{array}{c}\text { Intake } \\
(\mathrm{mm})\end{array}$ & $\begin{array}{c}\text { Infiltration } \\
\text { rate } \\
(\mathrm{mm} / \mathrm{min})\end{array}$ & $\begin{array}{c}\text { Infiltration } \\
\text { rate }(\mathrm{mm} / \mathrm{h})\end{array}$ & $\begin{array}{c}\text { Cumulative } \\
\text { infiltration } \\
(\mathrm{mm})\end{array}$ \\
\hline $\mathrm{O}$ & $\mathrm{O}$ & $\mathrm{O}$ & $\mathrm{O}$ & $\mathrm{O}$ & & \\
\hline 0.5 & 0.5 & 0.008333333 & 1.05 & 2.1 & 126 & 1.05 \\
\hline 1 & 0.5 & 0.008333333 & 0.97 & 1.94 & 116.4 & 2.02 \\
\hline 2 & 1 & 0.016666667 & 0.95 & 0.95 & 57 & 2.97 \\
\hline 3 & 1 & 0.016666667 & 0.88 & 0.88 & 52.8 & 3.85 \\
\hline 4 & 1 & 0.016666667 & 0.83 & 0.83 & 49.8 & 4.68 \\
\hline 6 & 2 & 0.033333333 & 1.2 & 0.6 & 36 & 5.88 \\
\hline 8 & 2 & 0.033333333 & 0.97 & 0.485 & 29.1 & 6.85 \\
\hline 10 & 2 & .0333 & 0.92 & 0.46 & 27.6 & 7.77 \\
\hline 12 & 2 & 0.033333333 & 0.89 & 0.445 & 26.7 & 8.66 \\
\hline 14 & 2 & 0.033333333 & 0.82 & 0.41 & 24.6 & 9.48 \\
\hline 18 & 4 & 0.066666667 & 1.25 & 0.3125 & 18.75 & 10.73 \\
\hline 22 & 4 & 0.066666667 & 1.15 & 0.2875 & 17.25 & 11.88 \\
\hline 26 & 4 & 0.066666667 & 1.05 & 0.2625 & 15.75 & 12.93 \\
\hline 34 & 8 & 0.133333333 & 0.95 & 0.11875 & 7.125 & 13.88 \\
\hline 42 & 8 & 0.133333333 & 0.92 & 0.115 & 6.9 & 14.8 \\
\hline 50 & 8 & 0.133333333 & 0.85 & 0.10625 & 6.375 & 15.65 \\
\hline 62 & 12 & 0.2 & 2.15 & 0.179167 & 10.75 & 17.8 \\
\hline 74 & 12 & 0.2 & 2.1 & 0.175 & 10.5 & 19.9 \\
\hline 86 & 12 & 0.2 & 1.85 & 0.154167 & 9.25 & 21.75 \\
\hline 106 & 20 & 0.333333333 & 3.1 & 0.155 & 9.3 & 24.85 \\
\hline 126 & 20 & 0.333333333 & 3.05 & 0.1525 & 9.15 & 27.9 \\
\hline 146 & 20 & 0.333333333 & 3 & 0.15 & 9 & 30.9 \\
\hline 166 & 20 & 0.333333333 & 3 & 0.15 & 9 & 33.9 \\
\hline 186 & 20 & 0.333333333 & 3 & 0.15 & 9 & 36.9 \\
\hline 206 & 20 & 0.333333333 & 3 & 0.15 & 9 & 39.9 \\
\hline
\end{tabular}

Table 6. Infiltration rate and cumulative infiltration at $\mathrm{T} 1$.

\begin{tabular}{|c|c|c|c|c|c|c|}
\hline $\begin{array}{c}\text { Elapsed } \\
\text { time } \\
(\mathrm{min})\end{array}$ & $\begin{array}{c}\text { Time interval } \\
(\mathrm{min})\end{array}$ & Time (h) & $\begin{array}{c}\text { Intake } \\
(\mathrm{mm})\end{array}$ & $\begin{array}{c}\text { Infiltration } \\
\text { rate } \\
(\mathrm{mm} / \mathrm{min})\end{array}$ & $\begin{array}{c}\text { Infiltration } \\
\text { rate } \\
(\mathrm{mm} / \mathrm{h})\end{array}$ & $\begin{array}{c}\text { Cumulative } \\
\text { infiltration } \\
(\mathrm{mm})\end{array}$ \\
\hline 0.5 & 0.5 & 0.008333333 & 1.2 & 2.2 & 144 & 1.2 \\
\hline 2 & 1.5 & 0.025 & 3.12 & 2 & 124.8 & 4.32 \\
\hline 7 & 2 & 0.033333333 & 2.26 & 0.81 & 67.8 & 9.98 \\
\hline 10 & 3 & 0.05 & 3 & 0.75 & 60 & 12.98 \\
\hline 13 & 3 & 0.05 & 2.96 & 0.575 & 59.2 & 15.94 \\
\hline 16 & 3 & 0.05 & 2.91 & 0.525 & 58.2 & 18.85 \\
\hline 32 & 4 & 0.066666667 & 2.4 & 0.43 & 36 & 29.65 \\
\hline 40 & 8 & 0.133333333 & 3.5 & 0.38 & 26.25 & 33.15 \\
\hline 48 & 8 & 0.133333333 & 3.2 & 0.33 & 24 & 36.35 \\
\hline 56 & 8 & 0.133333333 & 3 & 0.26 & 22.5 & 39.35 \\
\hline 66 & 10 & 0.166666667 & 3.4 & 0.21 & 20.4 & 42.75 \\
\hline 76 & 10 & 0.166666667 & 3.2 & 0.232 & 19.2 & 45.95 \\
\hline 86 & 10 & 0.166666667 & 3 & 0.21 & 18 & 48.95 \\
\hline 98 & 12 & 0.2 & 3.55 & 0.19 & 17.75 & 52.5 \\
\hline 110 & 12 & 0.2 & 3.45 & 0.175 & 17.25 & 55.95 \\
\hline
\end{tabular}




\section{CONCLUSION}

In this research, performance measures for the Melka Hida community-managed furrow irrigation scheme were evaluated. The performance measures used were the efficiency of application, distribution uniformity, and water storage, deep percolation ratio, and tail water runoff ratio. These parameters were evaluated at $\mathrm{H}_{1}, \mathrm{M}_{1}$, and $\mathrm{T} 1$ in the irrigation scheme.

Performance showed variation based on plot and irrigation event variation in the system. Water application efficiency ranged between 57 and $64 \%$, with an average of $61 \%$ across the scheme.

Excess wastage of irrigation water was found, resulting from deep percolation and tail water runoff. Steep slopes, long cutoff times, and inflow rate greater than soil infiltration rate were revealed as the key factors. Other factors identified included lack of attention during irrigation application, absence of a water control structure, and irregular furrow construction by farmers. In addition, the effectiveness of the water users' association was poor in regard to irrigation system management due to a knowledge gap and financial constraints. The efficiency of application of irrigation water at the farm level was poor, particularly in T1. In conclusion, the need for further improvements in irrigation is required in this scheme.

Funding: This study received no specific financial support.

Competing Interests: The authors declare that they have no competing interests.

Contributors/Acknowledgement: Both authors participated equally in the design and performance of the current research.

Views and opinions expressed in this study are those of the authors views; the Asian Journal of Agriculture and Rural Development shall not be responsible or answerable for any loss, damage, or liability, etc. caused in relation to/arising out of the use of the content.

\section{REFERENCES}

Abebe, S. (2015). Performance assessment irrigation schemes cccording to comparative indicators: A case study of Shina-Hamusit and Selamko, Ethiopia. International Journal of Scientific and Research Publications, 5(12), 451-460.

Awulachew, S. B., \& Ayana, M. (2011). Performance of irrigation: anassessment at different scales in Ethiopia. Expl Agric, Cambridge University Pres (2011), 47(S1), 57-69.

Beshir, A., \& Bekele, S. (2006). Analysis of irrigation systems using comparative performance indicators: A case study of two large scale irrigation systems in the upper wash basin. Addis Ababa: Unpublished Thesis.

Food and Agriculture Organization. (1989). Guidelines for designing and evaluating surface irrigation system. Irrigation and Drainage Paper. No. 45

Food and Agriculture Organization. (1992). CROPWAT, a computer program for irrigation planning and management. Irrigation and Drainage: Paper No. 46.

Food and Agriculture Organization. (2002). Monitoring the technical and financial performance of an irrigation scheme. Harare: FAO.

Food and Agriculture Organization. (2011). The states of the world land and water resources for food and agriculture. Rome: FAO of the United Nations and London, Earth Scan.

Holzapfel, E. A., Pannunzio, A., Lorite, I., Silva, D. O. A. S., \& Farkas, I. (2010). Design and management of irrigation systems. Chilean Journal of Agricultural Research, 69(Suppl. 1), 17-25.

Kulapongse, P. (1966). Factors affecting efficiencies of furrow irrigation. Thesis-Reproduction (Electronic), the University of Arizona.

Mancosu, N., Snyder, R. L., Kyriakakis, G., \& Spano, D. (2015). Water scarcity and future challenges for food production. Water, 7(3), 975-992.Available at: https://doi.org/10.3390/w7030975.

Michael, A. M., Mohanshri, A., \& Swaminthan, K. R. (1972). Design and evaluation of irrigation methods. New Delhi: Water Technology Centre, Indian Agricultural Research Institute.

Ministry of Agriculture. (2011). Guideline irrigation agronomy. AddisAbeba, Ethiopia: NRM September.

Pearse, T. L. (1973). Furrow irrigation evaluation. Paper presented at the Rhodesia Sugar Association Experiment Station, Proceedings of the South African sugar Technologists' Association.

Thakur, R. K., Baghel, S. S., Sharma, G. D., Sahu, R. K., \& Amule, P. C. (2012). Training programme on advances in agro-technologies for improving soil, plant and atmosphere systems. Jabalpur 482004 (MP): Laboratory Manual, Jawaharlal Nehru Agricultural University. 